CORRECTION

\title{
Correction: Case-cohort design in hematopoietic cell transplant studies
}

\author{
Jianwen Cai iD and Soyoung Kim (iD \\ (c) The Author(s), under exclusive licence to Springer Nature Limited 2021
}

Bone Marrow Transplantation (2022) 57:145; https://doi.org/10.1038/s41409-021-01522-4

In addition the Series Editors' Note was missing from this article and should have read:

Imagine you and your colleagues have done 1000 transplants in persons with acute myeloid leukaemia (AML) in 1st remission. 5 percent of the 20 percent of recipients relapsing posttransplant have an isolated central nervous system relapse. You are curious and want to know whether there is anything special about this 5 percent, specifically whether this risk corelates with any pretransplant clinical and laboratory co-variates. You have extensive clinical data and some typical laboratory data on all 1000 but you suspect the culprit is mutation topography. What to do? Fortunately you have bio-banked DNA from the 1000. If resources and monies are not limiting you can do targeted or next generation sequencing on all 1000 DNA samples and off you go. However, most of us lack unlimited resources and monies. How can you sensibly and efficiently tackle this research problem? The answer is a case-cohort design study. In the typescript which follows Profs. Cai and Kim explain how to accomplish this. If you follow their advice you may need only to analyze samples from < 300 recipients rather than 1000 to test your hypothesis. They explain how to design such a study and provide references to estimate sample size.

Sadly, their typescript will not tell you how to get funding for the study, whish poor devil who will have to write the protocol, worse, who will shepherd it though endless committees for approval and the like. Help on these issues is outside the scope of our statistics series. In this context we suggest advice from Woody Allen's article in the New Yorker: The Kugelmass Episode (April 24, 1977). When Prof. Kugelmass (English, City College) tells his analyst Dr. Mandel he has fallen in love with Emma Bovary who died of arsenic poisoning near Rouen, France 120 years earlier the analyst says: After all, I'm an analyst, not a magician. Kugelmass' reply: Then perhaps what I need is a magician and is off to Coney Island to find one. Good luck, the magician may still be there! (Note: This typescript is R-rated. It contains an equation.)

Robert Peter Gale, Imperial College London, and Mei-Jie Zhang, Medical College of Wisconsin and CIBMTR.

Correction to: Bone Marrow Transplantation https://doi.org/10.1038/ s41409-021-01433-4, published online 16 August 2021

The grant support number U24CA233032 was given incorrectly should not have been included in the publication and has been removed entirely.

The original article has been corrected. 